fall on the boat. They were followed by small pellets, which rattled on the deck like a shower of peas. In a minute or two fine grey ash, moist and clinging together in small globules, poured down upon us. After that for some time there was a rain of dry grey ashes. But the cloud had lost most of its solid matter, and as it shot forwards over our heads it left us in a stratum of clear pure air. When the fine ash began to fall there was a smell of sulphurous acid, but not very marked. There was no rain.

The volume of steam discharged must have been enormous, for the tongue-shaped cloud broadening as it passed southwards covered the whole sky except a thin rim on the extreme horizon. Dust fell on Fort de France and the whole south end of Martinique. The display of lightning was magnificent. It threaded the cloud in every direction in irregular branching lines. At the same time there was a continuous low rumble overhead.

What happened on Mont Pelée after this discharge cannot be definitely ascertained. For some hours afterwards there were brilliant lightnings and loud noises which we took for thunder. That night there was a heavy thunderstorm over the north-end of Martinique, and much of the lightning was atmospheric, but probably the eruption had something to do with it, and the noises may have been in part of volcanic origin.

\section{Characteristics of the Eruptions.}

There can be no doubt that the eruption we witnessed was a counterpart of that which destroyed St. Pierre. The mechanism of these discharges is obscure, and many interesting problems are involved. But we are convinced that the glowing avalanche consisted of hot sand and gases-principally steam; and when we passed the hill in R.M.S. Wear a few days later, we had, by the kindness of the captain, an excellent opportunity of making a close examination of the shore from the bridge of the steamboat. The south-west side of the hill along the course of the Rivière Seche was covered with a thin coating of freshly fallen fine grey ashes, which appeared to be thickest in the stream valleys. The water of the rivers flowing down this part of the hill was steaming hot. This was undoubtedly the material emitted from the crater on the night of the eruption. There was no lava. We saw no explosions of combustible gases, and nothing like a sheet of flame. We were agreed that the scintillations in the cloud were ordinary lightnings which shot from one part of its mass to another, and partly also struck the sea beneath.

The most peculiar feature of these eruptions is the avalanche of incandescent sand and the great black cloud which accompanies it. The preliminary stages of the eruption, which may occupy a few days or only a few hours, consist of outbursts of steam, fine dust and stones, and the discharge of the crater lakes as torrents of water or of mud. In them there is nothing unusual, but as soon as the throat of the crater is thoroughly cleared, and the climax of the eruption is reached, a mass of incandescent lava rises and wells over the lip of the crater in the form of an avalanche of red-hot dust. It is a lava blown to pieces by the expansion of the gases it contains. It rushes down the slopes of the hill, carrying with it a terrific blast, which mows down everything in its path. The mixture of dust and gas behaves in many ways like a fluid. The exact chemical composition of these gases remains unsettled. They apparently consist principally of steam and sulphurous acid. There are many reasons which make it unlikely that they contain much oxygen, and they do not support respiration.

\section{THE PERSEID METEORIC SHOWER OF I9O2.}

THE display of Perseid meteors was fairly abundant this year, though somewhat marred, and only partially observed, in consequence of the unsettled weather which prevailed. In the west of England the first half of August proved an exceptionally cloudy period, and comparatively few observations could be secured. In the eastern counties atmospheric conditions appear to have been decidedly more favourable, for while at Bristol only meagre results could be gathered from skies wholly or partially veiled with clouds, observers in metropolitan suburbs reported clear weather and collected a plentiful harvest of meteor flights. At Hampstead Mr. G. M. Knight counted 500 meteors during the first fortnight of August. Between August $I$ and 5, 167 were recorded, and on August IO, from NO. I 7 I 2, VOL. 66]
IIh. $30 \mathrm{~m}$. to $15 \mathrm{~h}$. $15 \mathrm{~m}$., 239 were seen. The majority of them were Perseids of the usual swift, streak-leaving type, and there were minor showers in Cassiopeia, Andromeda, Cepheus and other regions. Mr. Knight has forwarded the writer some charts containing projections of his recorded paths, and the place of the Perseid radiant appeared to be indicated as under. The ephemeris positions given in the Monthly Notices, December, I90I, p. 169, are also added for comparison :-

$$
\begin{aligned}
& \text { 1902. Radiant. } \begin{array}{c}
\text { No. of- } \\
\text { meteors. Ephemeris. }
\end{array} \\
& \text { August } 1-3 \ldots 37+55 \cdots 12 \ldots 33^{\circ} 9+55^{\circ} 0
\end{aligned}
$$

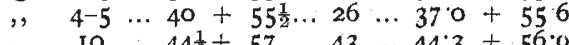

$$
\begin{aligned}
& \text { " } 10 \ldots 44 \frac{1}{2}+57 \ldots 43 \ldots 44.3+56.9
\end{aligned}
$$

The agreement is fairly good, though the places observed this year in the early part of August are somewhat east of the predicted centres. A certain allowance has, however, to be made for errors of observation.

At Bristol the writer watched for the Perseids on parts of the nights of August 2, 6, ro, 12 and 14 , but clouds prevented any. thing like a thorough investigation of the progress of the display. The Perseids were fairly numerous, and shot from the radiants given below, but very few meteors were seen on August 6 and I4 owing to the clouds, so that the points of emanation on those

\begin{tabular}{|c|c|c|c|c|c|}
\hline xgo2. & & & Radiant. & & Ephemeris. \\
\hline Augius & 6 & $\ldots$ & $39+57$ & $\ldots$ & $3^{8} \cdot 9+5^{\circ}$ \\
\hline & 10 & $\ldots$ & $45+58 \frac{1}{2}$ & $\ldots$ & $443+5^{6} \cdot 9$ \\
\hline & I 2 & .. & $47+5^{8 \frac{1}{2}}$ & ... & $47 \cdot \mathrm{I}+573$ \\
\hline & I4 & $\ldots$ & $50+57$ & $\ldots$ & $50^{\circ} 0+57$ \\
\hline
\end{tabular}
nights were merely suspected :-

The year 1900 not having been a leap-year, the maximum was expected on either August II or I2. There was an unusually bright exhibition of these meteors on August II, I898. It seems that the maximum intensity was well defined this year, for " a magnificent shower of Perseids" is reported to have been witnessed at Odessa on Tuesday night, August 12. The chief radiating point is said to have been at an altitude of $45^{\circ}$ or $50^{\circ}$ in the north-east firmament. The latter position corresponds approximately with the normal place of the Perseid centre. But, unfortunately, the report mentions no details as to the number of meteors observed or the duration of the observa. tions, and it is impossible, therefore, to form any exact conclusion as to the character of the display witnessed. It will probably be found, however, when particulars come to hand, that it represented nothing more than a tolerably plentiful return of the stream. There are no other descriptions favouring the inference that a strikingly brilliant shower was witnessed. In and since I 898 the Perseids appear to have been richer than usual, though it is extremely difficult to ascertain the relative strength of the shower from year to year owing to the variable conditions affecting the visibility of the meteors. W. F. DENNING.

\section{THE ZOOLOGICAL SOCIETY'S NEW $A P E-H O U S E$.}

THE ordinary plan of keeping monkeys in zoological gardens is to house them in cages which, while closed in winter, can be opened to playing-places in the external air in summer. The objection to this course is that, though it gives the great advantage of fresh air, the monkeys emerging from a heated chamber into a cooler atmosphere are very liable to catch cold and suffer from pulmonary complaints. In the case of some of the hardier Quadrumana (such as the Tcheli monkey of Mantchuria and the Cape baboon), there can be no doubt that such animals will thrive best without artificial warmth of any kind beyond the protection of a dry roof, and may be kept in the open air all the year round. This plan, however, would hardly answer in the case of the anthropoid apes, which live in hot, moist climates and are accustomed all their lives to a high and uniform temperature. In constructing the new ape-house for the special accommodation of these animals, the Zoological Society has adopted the plan, which has been tried with some success on the continent, of separating the animals entirely from the evils of a changeable climate by an air-tight glass screen through which only they can be seen by the public. The 
further advantage of this plan is that the apes can receive no germs of disease from the visitors, and can be kept behind the screen in a higher temperature than is maintained in the portion of the building allotted to the spectators

The new ape-house, for which there was much difficulty in finding a convenient site in the already crowded Gardens in the Regent's Park, is nearly square in shape, being about 70 feet in length and breadth. The principal floor is raised some 5 or 6 feet above the level of the ground, in order to secure the animals from the damp of the stiff clay soil upon which the house is built; and the chambers below the principal floor are devoted to the keeper's apartments and to feeding and heating purposes. On entering the spectators' portion, which occupies the north side of the building, by one of the flights of steps which ascend to the outside platform, the apes will be found occupying four large and roomy chambers on the south side. They are entirely separated from the spectators by the glass screen which runs across the building and corresponds to the windows of a fashionable shop in Regent Street. The spectators are on the outside of the screen and the objects to be inspected on the inside. They are in a good light because the interior is made bright and clear by skylights and by four large windows which occupy the south aspect of the building, while the spectators stand in a darker light. The screen has the further advantage that the animals cannot be improperly fed or unnecessarily stirred up with sticks and umbrellas, as is too often the case in the ordinary monkey-house. The apes themselves can hardly be said to be in cages, but live in lange rooms some 16 fee square, which are fitted up with tree-branches, swings, and other contrivances for their amusement and exercise. All round these four rooms runs a narrow passage by which the keepers can gain access to any part of them. The temperature of the rooms for the animals is kept at from $80^{\circ}$ to $85^{\circ} \mathrm{F}$., while that of the portion of the huuse devoted to the spectators is usually from $10^{\circ}$ tc $15^{\circ}$ less.

The apes that at present tenant the new ape-house are some seven or eight in number, and consist of chimpanzees, orangs and gibbons, representing all the three usually distinguished genera of the anthropoid apes. Besides these, one of the compartments is occupied by a small individual of the very curious proboscis monkey of Borneo (Nasalis larvata), one of the most peculiar forms of Old-World monkeys. This has always been found to be a most delicate animal in captivity, and very few specimens of it have ever reached Europe alive. When adult the proboscis monkey is rather a large animal, measuring, perhaps, some 30 inches in the length of its body, while the tail is nearly as long. It is remarkable for its large and elongated nose, of which, however, there is comparatively little appearance in the ptesent young specimen. The young animal is also much more simple in coloration, being of a nearly uniform pale rufous above and grey below, while the adult is brightly and mostly distinctly coloured with yellow and chestnut. The proboscis monkey is an inhabitant of Borneo, and was made known to European science by Wurmb, the I)utch Governor of Batavia about 1780 . Preserved specimens of it were first brought to Europe by Sir Stamford Raffles. Captain Stanley Flower received some living examples of it at the Ghizeh Gardens, Cairo, in 1899 (see P.Z.S., 1899 , p. 785), but they did not last long even in the favourable climate of Egypt.

THE HABITS OF THE LARVE AND ADULTS OF SIREX AND THALESSA.

$\mathrm{W}^{\mathrm{E}}$ have received from $\mathrm{Mr}$. F. P. Stebbing, of Dehra Dun, India, an account of the habits of the larva of a Himalayan species of sawfly (Sirex) and its parasite, an ichneumon allied to Thalessa, of which the following is an epitome. The adult sawfly deposits its eggs in the wood of dead spruce-trees (Picea morinda). When hatched, the grubs bore horizontally into the wood for a short distance and then drive a tunnel vertically upwards or downwards after the manner of the European S.augur. The débris, after passing through the body of the grub, is so closely jammed in the tunnel that no holes are visible in the wood when sawn through. The pupa is formed at the end of the tunnel, where it lies naked at an angle to the axis of the stem at a variable distance from the exterior. In place of following the old, tortuous track of the grub-for several reasons a matter of difficulty-the aduit insect cuts its way to the exterior by the nearest route, which, unlike that of the European species, is not, as a rule, at right angles to the tarval tunnel.
The mature insect never seems to have the slightest hesitation in determining the direct route to the outer world. It may be added that the larval state seems to last for several years, as grubs of different ages occur in the same trunk.

With regard to the parasitic ichneumon-fly allied to or identical with Thalessa, Mr. Stebbing is of opinion that it never makes the mistake of attacking wood in which pupæ of the sawfly Sirex are not entombed. As to the statement that the ichneumon-fly frequently dies from its ovipositor becoming inextricably fixed in the wood, he suggests that the insect, after depositing its last egg, dies in the position then assumed, as is certainly the case with many of the hark-boring beetles of the family Scolytidix. As the ovipositor of the ichneumon does not exceed an inch and a half in length, while the spruce-bark may be fully an inch thick, it is considered that the Thalessa must have some means of fixing the position of the Sirex eggs and of the tunnels of the young grubs in the wood underlying the bark. Without such knowledge it would seem an impossibility for the parasite, the ovipositor of which appears of inadequate length for its task, to reach the larval tunnels. Numbers of dead ichneumons were observed in partially bored galleries, this being apparently due to the circumstance that the Sirex larva often travel with their parasites to such a depth in the trunk that the adults of the latter are unable to cut their way out. The numbers of the ichneumon are thus, involuntarily, kept down by the sawfly larva.

\section{UNIVERSITY AND EDUCATIONAL INTELLIGENCE.}

Mr. J. GrahaM KerR, of Christ's College, Cambridge, has been appointed professor of natural history in the University of Glasgow, in succession to Prof. John Young, who has resigned.

THE Martell scholarsbip in naval architecture, offered for competition for the first time this year, has been awarded by the council of the Institution of Naval Architects to Mr. L. Woollard, of the Thames Ironworks, Blackwall. The scholarship is of the annual value of $50 l$. and is tenabie for three years.

A.s exhibit to illustrate the state of education in the British Empire will be sent by the Government to the Universal Exposition to be held in St. Louis in 1904. The official exhibits will be limited to education and the fine arts, but facilities will be afforded to trade and individual exhibitors to show products representing British industries.

THE last annual report of the Technical Instruction Committee recently presented to the Oxfordshire County Council supplies further evidence of the serious deficiency in the supply of secondary education in many parts of the country, which it is hoped the passing of the Education Bill, now before Parliament, will do much to remedy. The Committee again directs attention to the lack of secondary schuols for girls throughout Oxfordshire, and for boys in the district between Chipping Norton and Bicester. In other directions favourable conditions mark the educational activity of the Committee ; there has been a general improvement in the agricultural instruction in the rural centres, and good work has been done in supplementing the training of elementary school teachers.

IN accordance with the action of the Board of Trustees and the provisions of the will of the late Jonas G. Clark, the founder, the collegiate department of the Clark University, Worcester, Massachusetts, will be opened on October I. There is to be no charge for tuition for the year ending 1903 ; for the next year the charge is to be twenty-five, and for the third year fifty dollars. After the third year, the charge per student in all classes will be at a rate to be fixed by the Board of Trustees. The preliminary announcement issued by the president of the college, Dr. Carroll D. Wright, shows, amongst other provisions, that mathematics will be taught as the groundwork of the college education and that sports will be permitted solely "for the development of physical and moral conditions." Special attention is in the future to be given to the "new" psychology, to economics and to sociology.

Tine Volta Bureau of Washington, U.S.A., for the increase and diffusion of knowledge relating to the deaf, has issued its second international report of schools for the deaf. The data brought together from all parts of the world give a gratifying assurance that a marked improvement has taken place since 